\title{
Thrombin-Antithrombin Complex
}

National Cancer Institute

\section{Source}

National Cancer Institute. Thrombin-Antithrombin Complex. NCI Thesaurus. Code C17272.

A protease involved in clotting 